\title{
Friendship and Loneliness Among Bullies and Victims: Data From Seven Countries
}

\author{
Mike Eslea, ${ }^{* 1}$ Ersilia Menesini, ${ }^{2}$ Yohji Morita, ${ }^{3}$ Mona O’Moore, ${ }^{4}$ \\ Joaquin A. Mora-Merchán, ${ }^{5}$ Beatriz Pereira, ${ }^{6}$ and Peter K. Smith ${ }^{7}$ \\ ${ }^{1}$ Department of Psychology, University of Central Lancashire, United Kingdom \\ ${ }^{2}$ Department of Psychology, University of Florence, Italy \\ ${ }^{3}$ Department of Sociology, Osaka City University, Japan \\ ${ }^{4}$ Education Department, Trinity College, Dublin, Ireland \\ ${ }^{5}$ Department of Developmental and Educational Psychology, University of Seville, Spain \\ ${ }^{6}$ Institute of Childhood Studies, University of Minho, Portugal \\ ${ }^{7}$ Department of Psychology, Goldsmiths College, University of London, United Kingdom
}

\begin{abstract}
Research suggests that the relationship between school bullying and its various risk factors should be clearer among girls than boys, and should become stronger with age, as roles within the peer group stabilise. This paper tests this theory by comparing sex, school type, and bully/victim status differences in friendships and playground social interactions, using data from nine surveys in seven countries: China, England, Ireland, Italy, Japan, Portugal, and Spain. A total of approximately 48,000 children completed various translations of the Olweus Bullying Questionnaire. Small but generally consistent main effects were found for sex and school type (boys and primary pupils enjoyed playtimes more and had more friends, but were also more likely to spend playtimes alone). Larger effects were consistently found for bully/victim status (victims were significantly worse off on all the measures in all the samples where a difference was found, while bullies and neutrals did not differ consistently), but the interactions between these factors varied widely between samples and there were few consistent patterns. It is concluded that bullying is a universal phenomenon with many negative correlates for victims and few (if any) for bullies, but that there are cultural variations in the way that bullying is related to sex, age, and social support. Aggr. Behav. 30:71-83, 2004. (C) 2004 Wiley-Liss, Inc.
\end{abstract}

Keywords: bullying; victimization; friendship; loneliness

\section{INTRODUCTION}

School bullying first became a topic for psychological research with the work of Olweus in Scandinavia in the 1970s [Olweus, 1978]. Since then, surveys have been conducted in many

\footnotetext{
*Correspondence to: Dr Mike Eslea, Department of Psychology, University of Central Lancashire, Preston PR1 2HE, UK. E-mail: mjeslea@uclan.ac.uk
}

Received 25 April 2002; Amended version accepted 14 November 2002

Published online in Wiley InterScience (www.interscience.wiley.com). DOI: 10.1002/ab.20006 
countries around the world, all showing that bullying is a significant problem for large numbers of children [Smith et al., 1999b]. More recently, the focus of research has moved from studies of the nature and incidence of bullying to researching the causes, consequences, and correlates of victimisation [Hodges and Perry, 1996]. In particular, the group dynamics of the peer relationships underlying bullying have become a major focus of attention.

The status of bullies and of victims is generally clear in the peer group. Bystanders are present in $85 \%$ of bullying episodes [Pepler and Craig, 1994], and bullying has been shown to be a group process in which $63 \%$ of children play a "participant role" such as bully, victim, defender, bully's assistant, or reinforcer [Salmivalli et al., 1996]. Peer nominations for both bullies and victims can readily be obtained [Perry et al., 1988], show reliability and consistency [Boulton and Smith, 1994], and compare moderately well with self-report measures [Ahmad and Smith, 1990, Menesini and Giannetti, 1997] both for bullies and victims [Salmivalli et al., 1996].

Bullies are described by peers as disruptive and likely to start fights, victims as being shy and likely to seek help; with both being low on co-operation [Nabuzoka and Smith, 1993]. In part, these status differences in the peer group may be due to behavioural qualities of the children; for example lower social skills in victims [Boulton and Smith, 1994; Olweus, 1991], aggressiveness in bullies [Olweus, 1991], and low self-esteem in bullies, victims, and (especially) bully-victims [O'Moore and Kirkham, 2001]. These factors may interact with social risk factors in the peer group itself, such as friendship structure, and reputation [Cicchetti and Bukowski, 1995, Pellegrini et al., 1999].

Hodges and Perry [1996] suggest that there are three main social risk factors for victimisation: having few friends; having friends who are unable to help or protect you; and being rejected by the peer group. Work in the USA [Perry et al., 1988] and in England [Boulton and Smith, 1994; Nabuzoka and Smith, 1993] shows that victims and bullies are over-represented in the sociometric 'rejected' category (that is, they receive many 'like least' and few 'like most' nominations from classmates). Furthermore, victims are less likely to have a "best" friend or high quality friendship [Boulton et al., 1999]. In a study of English children, Boulton and Underwood [1992] found that victims reported having fewer friends and were more likely to spend breaktimes alone than controls. Similarly, in a study of US kindergarten children, Kochenderfer and Ladd [1996] found that victims scored higher on a scale of loneliness in school. Kochenderfer and Ladd [1997] further examined the characteristics of victims, finding that those who "get a friend to help them" were most likely to be able to stop the bullying. Those for whom victimisation continued did not have fewer friends, but either they lacked the skills to recruit help from these friends, or the friends lacked the ability to provide effective support.

One very robust finding (at least in cross-sectional research) is that the number of children reporting being bullied tends to fall with age [Smith et al., 1999a]. Frequency of incidents is therefore generally lower in secondary schools than in primary, after an initial rise particularly among boys, who use aggression to establish dominance in new groups, but then use it less once the hierarchy emerges [Pellegrini and Long, 2002]. As Smith et al. [2001] have pointed out, this trend means that the relationship between bullying and its various risk factors should become stronger and more reliable in older childhood. This is because early interactions are likely to fluctuate more as children try out different roles, learn new social skills (including skills such as fighting), and develop friendship networks. Most children can probably expect to experience some bullying or teasing in their early school years, but those who continue to be victimised will tend to be those who have failed to cope adequately 
(for whatever reason). Also, those children who continue to bully others will be those for whom bullying has been successful in the past, gaining them status and popularity.

The higher likelihood of relational bullying among girls might lead one to expect that social risk factors will be more closely related to bully/victim status among girls than among boys. Combining these arguments suggests that this relationship will be strongest among older girls, and weakest among younger boys. This paper tests this theory by examining school type and sex differences in the relationship between bully/victim status and a number of variables related to popularity, social support, and friendships. Since much previous research has been conducted in Scandinavia and the UK, we will try to determine if these findings can be generalised, and applied to a number of countries, both in Europe and the Far East.

\section{Predictions}

It is predicted that bully/victim status differences will be reliably identified in all countries: victims and bully-victims will have fewer friends, be more often isolated or excluded, and will enjoy school less, than bullies and controls. These group differences will be larger among older (secondary) pupils than younger (primary) pupils, and larger among girls than boys. The largest differences will therefore be for older girls and the smallest for younger boys.

\section{METHOD}

Survey data was obtained from large samples in China [Wakefield et al., 2000; Zhang et al., 2000], Ireland [O’Moore et al., 1997], Japan [Morita et al., 1999], Portugal [Pereira et al., 1996], and Spain [Ortega and Mora-Merchan, 1999]. Data for England comes from two surveys: one in the industrial city of Sheffield [Whitney and Smith, 1993] and one using a national sample [Smith and Shu, 2000]. Italian data also comes from two surveys: one in the prosperous city of Florence, and one from the smaller, Southern city of Cosenza [Genta et al., 1996]. Exact sample sizes are shown in Table I, which also shows the proportion of children in each survey attending either primary or secondary schools. The distinction between primary and secondary varies somewhat between (and sometimes within) the different countries, but the samples are broadly comparable with most children changing schools at around 11 years of age (slightly earlier in China and Portugal., slightly later in Spain).

These studies have previously been reported in relation to the nature and incidence of bullying, but they also provide an opportunity to examine data relevant to social risk factors affecting victims and bullies. The surveys, based on modified versions of the Olweus questionnaire (the 1991 version in most cases, the updated 1996 version in the English national survey and in Japan), include items about liking playtime, being alone at playtime, the number of good friends a child has, and their perceptions of their own popularity at school. Although based only on self-report data, the large sample sizes enable a clear look at school-type and sex differences in relation to bully/victim status, including also the less frequently studied subgroup of bully-victims (children who report both being bullied and bullying others; Bowers et al., 1994]. 


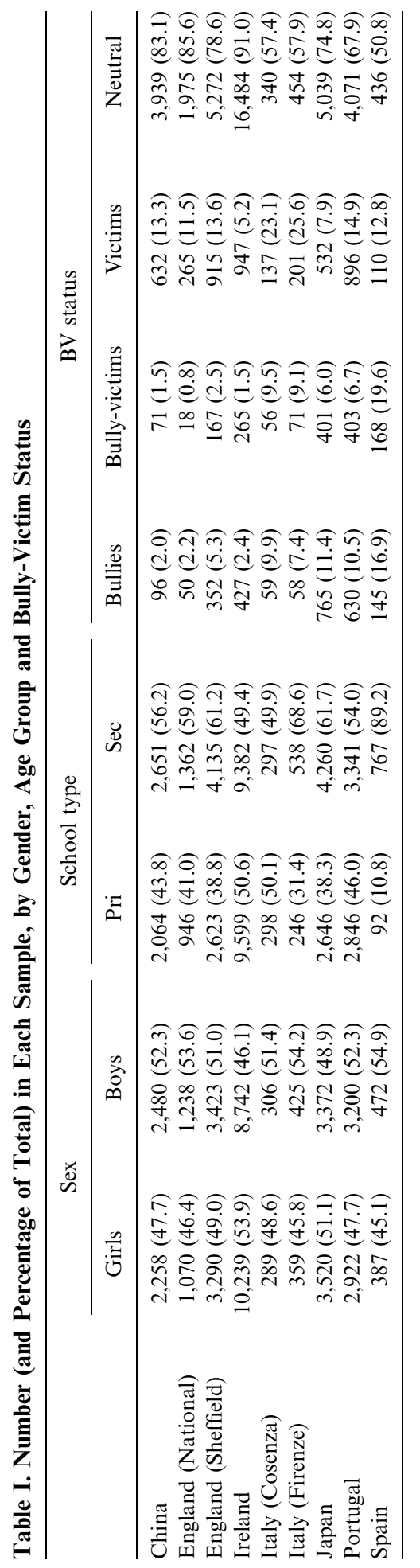




\section{Procedure}

The various groups of researchers used very similar methodology, using translations of the same definition of bullying and questionnaire, although the latter was slightly adapted for use in the different countries and sometimes presented the items in a different order. The English word "bullying" has no direct translation in most other languages [Smith et al., 2002], so the closest local approximation was used and a definition read to the pupils to make the meaning clear. For example, the definition provided with the 1991 (English) version of the Olweus questionnaire is as follows:

"We say that a child is being bullied, or picked on, when another child or a group of children say nasty or unpleasant things to him or her. It is also bullying when a child is hit, kicked, threatened, locked inside a room, sent nasty notes, or when no-one ever talks to them and things like that. These things can happen frequently, and it is difficult for the child being bullied to defend himself or herself. It is also bullying when a child is teased repeatedly in a nasty way. But it is not bullying when two children of about the same strength have the odd fight or quarrel." (The term 'young person' rather than 'child' was used for secondary school pupils. Similarly, the questionnaires for secondary pupils referred to 'breaktime' rather than 'playtime.')

Two questions identified bullies and victims: "How often have you been bullied at school this term?" and "How often have you taken part in bullying other children at school this term?" The possible responses in each case were: "I haven't been bullied (bullied other children) at school this term," "It has only happened once or twice," "Sometimes," "About once a week," or "Several times a week." For these and other questions, 'this term' referred to the 10-12 week period before the questionnaire was given.

Those pupils who checked "sometimes" or more frequently (i.e. those who reported being bullied, or bullying others, more than just once or twice) were categorised as 'victims' and 'bullies' respectively. Those who would thus be classed as both a 'victim' and a 'bully' were categorised as 'bully-victims'. Other children were categorised as 'neutrals' or controls. The number of children in each of these categories found in each survey is shown in Table I. The exact wording of the English versions of the items addressing friendships and playtime can be seen in Table II.

\section{RESULTS}

The first results to be considered are the bully/victim status group totals shown in Table I. It should be noted, however, that any international comparisons of the extent of bully/victim problems should be treated with extreme caution, since (as noted above) there are many variations in definitions and conceptions of bullying in different cultures and languages. There are also many differences in the proportions of children in each school type (and, to a lesser extent, the proportions of boys and girls) in the various samples. These differences, rather than differences in actual behaviour, may account for much of the variation shown in Table I, but they are unlikely to account for it all. The range is surprisingly large: the proportion categorised as victims of bullying ranges from just $5.2 \%$ in Ireland to $25.6 \%$ in Italy (Florence), while the number of bullies goes from only $2.0 \%$ in China to $16.9 \%$ in Spain. Bully-victims make up just $0.8 \%$ of the English (national) sample, but form $19.6 \%$ of the Spanish one. Conversely, only $50.8 \%$ of Spanish children were not involved in bullying at all, compared with $91 \%$ of children in Ireland. 
Table II. Mean Scores, by Sex, School Type and Bully/Victim Status, for Each Question for Each Survey

\begin{tabular}{|c|c|c|c|c|c|c|c|c|}
\hline & \multicolumn{2}{|c|}{ Sex } & \multicolumn{2}{|c|}{ School type } & \multicolumn{4}{|c|}{ BV status } \\
\hline & Girls & Boys & Pri & $\mathrm{Sec}$ & Bullies & $\begin{array}{l}\text { Bully- } \\
\text { victims }\end{array}$ & Victims & Neutral \\
\hline \multicolumn{9}{|c|}{ How much do you like playtime? $(1=$ dislike very much, $5=$ like very much) } \\
\hline China & 4.42 & 4.45 & 4.38 & 4.48 & 4.40 & 4.45 & 4.38 & 4.44 \\
\hline England (National) & 4.35 & 4.42 & 4.38 & 4.38 & 4.36 & 4.72 & 4.03 & 4.43 \\
\hline England (Sheffield) & 4.13 & 4.35 & 4.31 & 4.20 & 4.38 & 4.24 & 4.00 & 4.28 \\
\hline Ireland & 4.50 & 4.46 & 4.45 & 4.52 & 4.46 & 4.23 & 3.90 & 4.54 \\
\hline Italy (Cosenza) & 4.68 & 4.68 & 4.71 & 4.65 & 4.80 & 4.50 & 4.66 & 4.67 \\
\hline Italy (Firenze) & 4.63 & 4.59 & 4.61 & 4.61 & 4.78 & 4.55 & 4.56 & 4.67 \\
\hline Japan & 4.19 & 4.15 & 4.31 & 4.08 & 4.25 & 4.03 & 3.84 & 4.21 \\
\hline Portugal & 4.40 & 4.50 & 4.57 & 4.35 & 4.59 & 4.54 & 4.34 & 4.44 \\
\hline Spain & 4.61 & 4.52 & 4.52 & 4.61 & 4.78 & 4.64 & 4.29 & 4.54 \\
\hline
\end{tabular}

How often does it happen that other children don't want to spend playtimelbreaktime with you, and you end up being alone? (1 = never this term, $5=$ several times a week)

\begin{tabular}{|c|c|c|c|c|c|c|c|c|}
\hline China & 1.55 & 1.60 & 1.67 & 1.51 & 1.61 & 2.47 & 2.12 & 1.47 \\
\hline England (Sheffield) & 1.67 & 1.65 & 1.99 & 1.45 & 1.76 & 2.51 & 2.47 & 1.48 \\
\hline Ireland & 1.39 & 1.48 & 1.59 & 1.27 & 1.41 & 2.47 & 2.34 & 1.33 \\
\hline Italy (Cosenza) & 1.73 & 1.76 & 1.92 & 1.58 & 2.02 & 2.34 & 2.04 & 1.49 \\
\hline Italy (Firenze) & 1.82 & 1.69 & 2.09 & 1.59 & 1.45 & 2.14 & 2.16 & 1.54 \\
\hline Portugal & 1.29 & 1.30 & 1.35 & 1.34 & 1.29 & 1.51 & 1.55 & 1.21 \\
\hline Spain & 1.61 & 1.73 & 1.82 & 1.52 & 1.50 & 1.76 & 1.95 & 1.47 \\
\hline \multicolumn{9}{|c|}{ How many good friends do you have in your class? $(1=$ none, $4=$ many $)$} \\
\hline China & 3.63 & 3.67 & 3.67 & 3.63 & 3.66 & 3.71 & 3.49 & 3.67 \\
\hline England (National) & 3.52 & 3.48 & 3.44 & 3.56 & 3.61 & 3.34 & 3.32 & 3.75 \\
\hline England (Sheffield) & 3.50 & 3.53 & 3.50 & 3.53 & 3.54 & 3.33 & 3.24 & 3.57 \\
\hline Ireland & 3.58 & 3.61 & 3.63 & 3.56 & 3.67 & 3.39 & 3.15 & 3.63 \\
\hline Italy (Cosenza) & 3.39 & 3.59 & 3.57 & 3.41 & 3.41 & 3.32 & 3.34 & 3.60 \\
\hline Italy (Firenze) & 3.35 & 3.45 & 3.57 & 3.33 & 3.44 & 3.33 & 3.29 & 3.53 \\
\hline Japan & 3.83 & 3.73 & 3.84 & 3.75 & 3.85 & 3.67 & 3.51 & 3.81 \\
\hline Portugal & 3.69 & 3.69 & 3.70 & 3.67 & 3.74 & 3.61 & 3.68 & 3.71 \\
\hline Spain & 3.32 & 3.50 & 3.51 & 3.31 & 3.43 & 3.41 & 3.27 & 3.53 \\
\hline \multicolumn{9}{|c|}{ Do you feel you are less well-liked than other students in your class? $(1=$ no, never, $6=$ very often $)$} \\
\hline England (National) & 2.50 & 2.45 & 2.54 & 2.43 & 2.28 & 3.44 & 3.63 & 2.31 \\
\hline Japan & 2.27 & 2.60 & 2.36 & 2.47 & 2.39 & 3.03 & 3.20 & 2.31 \\
\hline
\end{tabular}

We will return to these differences in the discussion section. In the meantime, it seems clear that direct statistical comparisons between the various samples would not be appropriate. Instead, we examine each sample individually, comparing sex, school type, and bully/victim status differences in liking playtime, friendships, and loneliness, to see if consistent patterns will emerge. Mean scores for each question for each sample group are shown in Table II for each of the main subgroups: sex, school type (primary v secondary), and bully/victim status. These means were compared using $2 \times 2 \times 4$ ANOVA, and the resulting $F$ values are shown in Table III, together with an indication of their statistical significance. To make 
interpretation as simple as possible, given the number of comparisons involved, significant differences are discussed solely in terms of the group means without the benefit of post-hoc tests. We will begin with the main effects before turning to the interactions.

\section{Sex differences}

In total, eleven significant main effects of sex were identified. Boys reported liking playtime more (in China, Portugal, and Sheffield) and having more friends (Ireland and Cosenza), but

Table III. F Values from Multiple Analysis of Variance, for Each Question for Each Survey

\begin{tabular}{lccccccc}
\hline & \multicolumn{1}{c}{ Sex } & $\begin{array}{c}\text { School } \\
\text { type }\end{array}$ & BV status & $\begin{array}{c}\text { Sex by } \\
\text { school }\end{array}$ & $\begin{array}{c}\text { Sex by BV } \\
\text { status }\end{array}$ & $\begin{array}{c}\text { School by } \\
\text { BV status }\end{array}$ & $\begin{array}{c}\text { Sex by } \\
\text { school by } \\
\text { BV status }\end{array}$ \\
\hline How much do you like playtime? & & & & & & \\
\hline China & $21.4^{* * * *}$ & $10.7^{* * * *}$ & $6.1^{* * * *}$ & $13.1^{* * * *}$ & $8.5^{* * * * *}$ & $6.8^{* * * * *}$ & $6.5^{* * * *}$ \\
England (National) & 0.0 & 0.1 & $21.0^{* * * *}$ & 0.2 & 0.5 & 0.3 & 0.4 \\
England (Sheffield) & $20.1^{* * * *}$ & $6.2^{* *}$ & $34.5^{* * * * *}$ & $7.3^{* * *}$ & 0.1 & 0.4 & 0.5 \\
Ireland & $11.2^{* * * *}$ & $32.1^{* * * *}$ & $185.0^{* * * *}$ & $9.6^{* * *}$ & 2.2 & 0.9 & 0.7 \\
Italy (Cosenza) & 0.0 & 2.1 & 2.0 & 0.0 & 0.4 & 2.5 & 0.6 \\
Italy (Firenze) & 1.1 & 0.1 & $3.1^{*}$ & 1.8 & 0.2 & 0.8 & 0.9 \\
Japan & 2.6 & $52.0^{* * * *}$ & $35.9^{* * * * *}$ & 1.1 & 0.2 & 0.5 & 0.1 \\
Portugal & $6.1^{* * *}$ & $58.7^{* * * *}$ & $9.54^{* * * *}$ & 0.3 & 0.3 & 1.0 & 0.1 \\
Spain & 0.5 & 0.6 & $3.7^{*}$ & 0.3 & $5.2^{* * *}$ & 0.3 & $3.8^{*}$ \\
\hline
\end{tabular}

How often does it happen that other children don't want to spend playtimelbreaktime with you, and you end up being alone?

\begin{tabular}{lcccllcl}
\hline China & 0.2 & 0.7 & $118.4^{* * * *}$ & 0.7 & $6.6^{* * * *}$ & $2.9^{*}$ & $8.0^{* * * *}$ \\
England (Sheffield) & 0.2 & $87.9^{* * * *}$ & $255.0^{* * * *}$ & $4.3^{*}$ & 0.4 & $4.9^{* * *}$ & $3.2^{*}$ \\
Ireland & $46.4^{* * * *}$ & $755.9^{* * * *}$ & $706.5^{* * * *}$ & 0.1 & $4.9^{* * *}$ & $24.7^{* * * *}$ & 2.4 \\
Italy (Cosenza) & 0.0 & $12.7^{* * * *}$ & $18.1^{* * * *}$ & 0.1 & 0.8 & 1.2 & 1.0 \\
Italy (Firenze) & 1.7 & $26.4^{* * * *}$ & $18.1^{* * * *}$ & 2.9 & 0.6 & 1.2 & 0.5 \\
Portugal & $3.8^{*}$ & $24.0^{* * *}$ & $80.9^{* * * *}$ & $5.7^{* * *}$ & 1.8 & 1.3 & 0.8 \\
Spain & $4.1^{* *}$ & 1.0 & $6.5^{*}$ & 0.6 & 0.4 & 0.1 & 0.8 \\
\hline
\end{tabular}

How many good friends do you have in your class?

\begin{tabular}{lcccccll}
\hline China & 1.6 & 2.1 & $20.8^{* * * *}$ & 1.9 & 0.4 & 1.5 & 0.6 \\
England (National) & 2.2 & 2.2 & $37.9^{* * * *}$ & 0.5 & 0.8 & $1.9^{*}$ & 0.7 \\
England (Sheffield) & 0.3 & 3.6 & $65.7^{* * * *}$ & $9.0^{* * *}$ & $3.5^{*}$ & $9.0^{* * * *}$ & $4.1^{* * *}$ \\
Ireland & $7.3^{* *}$ & $63.8^{* * * *}$ & $170.4^{* * * *}$ & 0.7 & 0.9 & $4.1^{* * *}$ & 1.7 \\
Italy (Cosenza) & $9.3^{* *}$ & $7.3^{* *}$ & $5.8^{* * * *}$ & 0.2 & 1.9 & 1.1 & 0.8 \\
Italy (Firenze) & 3.2 & $216^{* * * *}$ & $5.5^{* * * *}$ & 0.2 & 0.8 & 0.6 & 1.5 \\
Japan & $6.4^{* *}$ & $37.5^{* * *}$ & $54.9^{* * * *}$ & 1.7 & 1.4 & 3.0 & 0.8 \\
Portugal & 0.2 & $19.6^{* * * *}$ & $4.7^{* *}$ & 0.3 & 0.2 & 1.2 & 1.8 \\
Spain & 1.0 & 2.3 & 2.6 & 0.2 & 1.2 & 0.0 & 0.2 \\
\hline Do you feel you are less & well-liked than other students in your class? & & & \\
\hline England (National) & 0.0 & $7.8^{* * *}$ & $102.4^{* * * *}$ & 0.1 & 1.4 & $4.1^{* * *}$ & 0.4 \\
Japan & $64.0^{* * * *}$ & $21.9^{* * * *}$ & $179.8^{* * * *}$ & 0.2 & 0.7 & 0.6 & 0.1 \\
\hline
\end{tabular}

$* \mathrm{p}<0.05$;

$* * \mathrm{p}<0.01$

$* * * * \mathrm{p}<0.001$. 
being left alone more often (Ireland, Portugal, and Spain) and feeling less well-liked (Japan) than girls. However, the opposite pattern was found in two cases: boys in Ireland reported liking playtime less, and boys in Japan reported having fewer friends, than girls did. Statistical significance notwithstanding, however, most of these differences were quite small, and both boys and girls scored close to the positive (i.e. prosocial) end of each scale in all the samples.

\section{Developmental trends}

The pattern of main effects found for the school type comparisons was much more consistent, despite the variations in the exact ages of the primary and secondary groups in the various samples. A total of 17 significant main effects were identified, almost all of which involved primary pupils obtaining higher mean scores than secondary pupils on the various items. Primary pupils enjoyed playtime more (Sheffield, Japan, and Portugal), had more friends (Ireland, Cosenza, Florence, Japan, and Portugal) but were left alone more often (Sheffield, Ireland, Cosenza, Florence, and Portugal) and felt less well liked (England) than their older counterparts. There were three exceptions to this pattern: in China and in Ireland, secondary pupils enjoyed playtimes more, and in Japan they were less well liked than primary pupils. In general, the mean differences for these school type comparisons were again quite small, but were larger than those reported for sex differences (above).

\section{Bully/victim status differences}

By far the largest differences were found for the main effects of bully/victim status. These were also the most numerous effects: significant in 25 of the 27 comparisons in the study. Patterns are somewhat harder to discern in four-group comparisons like this, but there were several apparent consistencies. Victims reported liking playtimes least of all in China, England, Sheffield, Ireland, Japan, Portugal, and Spain, whereas bullies enjoyed playtimes most in Sheffield, Florence, Japan, Portugal, and Spain. The children who reported being left alone at playtimes most often were always either victims (Florence, Portugal, and Spain) or bully-victims (China, Sheffield, Ireland, and Cosenza), while those left alone least often were almost always the neutrals (China, Sheffield, Ireland, Cosenza, Portugal, and Spain). Victims reported having fewest friends in China, England, Sheffield, Ireland, Florence, and Japan, and were least well-liked in both England and Japan. Those with the greatest number of friends were usually the neutrals (England, Sheffield, Cosenza, and Florence) or the bullies (Ireland, Japan and Portugal).

To summarise, the position with regard to victims, bullies, and neutrals seems clear: victims were significantly worse off on all the measures in all the samples where a difference was found, while bullies and neutrals did not differ consistently. No social disadvantages were found to be associated with bully status. The position of bully-victims is more complicated: in some respects they most resemble bullies and neutrals (liking playtime, for example) but in others they are more like victims (being left alone at playtimes and having fewer friends).

\section{Interaction effects}

Inevitably, the picture becomes rather more complicated when the interactions between sex, school type, and bully/victim status are considered. In contrast to the number of main effects, few significant interactions were identified, and there were few consistencies in the 
patterns found in the different samples. Furthermore, despite the large overall sample sizes, some of the subgroups were found to be extremely small. For example, the 1,300 Chinese secondary girls were found to include just one bully and two bully-victims. Consequently, these interaction effects should be interpreted with caution. More details of the subgroup means, and plots of the three-way effects, are available from the first author (or may be viewed online at http://www.uclan.ac.uk/facs/science/psychol/bully). In this section we will describe the overall patterns of interaction (such as they are) from each item in turn.

The item "How much do you like playtime?" produced a number of significant two-way interactions but little consistency across samples. For example, secondary girls enjoyed playtime more than any other group in China and in Ireland, but less than any other group in Sheffield. Girl bullies enjoyed playtime least in China, but most in Spain. Two significant three-way effects were also noted. Chinese primary girl victims enjoyed playtime more than controls, but although their liking did increase slightly in secondary school it was far outstripped by the increase among controls. For Chinese boys, however, there were no differences between primary and secondary school for either victims or controls, only an increase for bully-victims and a decrease among bullies. In Spain, boy victims always liked playtime less than other boys, but the gap did at least close between primary and secondary schools, whereas for girls the victims actually liked playtime more than controls while in primary school, but the situation reversed in secondary schools.

The picture for the item "How often does it happen that other children don't want to spend playtime/breaktime with you, and you end up being alone?"' is slightly clearer, at least in some places. The same sex-by-school interaction was found in both Sheffield and Portugal: girls reporting more frequent isolation than boys in primary school, but boys more than girls in secondary. Sex-by-bully/victim status interactions were found in China (boys more frequently isolated than girls in all bully/victim categories except bullies) and in Ireland (girls more frequently isolated than boys in all bully/victim categories except neutral). The Irish, Chinese, and Sheffield samples also produced significant school-by-bully/victim status interactions, showing that the more frequent isolation of victims and bully-victims (compared to neutrals and bullies) was particularly pronounced in secondary schools. In Sheffield, a significant three-way interaction effect revealed that both boys and girls of all bully/victim groups experienced less frequent isolation in secondary schools than in primary, except for boy victims, for whom there was no difference. In China, by contrast, there were only small differences between sexes or school types for victims and controls compared to the much larger school type differences for boy bullies (less isolation in secondary) and bully-victims (more isolation in secondary).

Analysis of the third item, "How many good friends do you have in your class?" produced a smaller number of significant interaction effects, most (including a three-way interaction) for the Sheffield sample. This showed that control children (all sex and school types) and bullies (at both ages for boys and in secondary only for girls) reported having the most friends. Victims always reported fewest friends, but for girls there was no school type difference while boy victims in secondary school reported having even fewer friends than those in primary. Elsewhere, two significant school-by-bully/victim status interactions were found. In the English (national) sample, the biggest difference was that bullies in secondary schools reported the most friends of all, but primary bullies had very few (the same as victims). In Ireland, by contrast, bullies in both school types had many more friends than victims or bully-victims. Finally, let us consider the item "Do you feel you are less well-liked than other students?" which produced a significant school-by-bully/victim status interaction 
in England. As for the previous item, the biggest difference here was that secondary bullies reported being the most liked of all, while primary bullies were way behind, along with the victims and bully-victims.

\section{DISCUSSION}

It was predicted that the analysis described in this paper would reveal consistent patterns in sex, school type, and bully/victim status differences in friendships and loneliness at school. At one level, this objective was successfully met: significant main effects for all three factors were identified and, in general, similar differences were found in most of the different samples. Boys and primary pupils enjoyed playtimes more and had more friends, but were also more likely to spend playtimes alone. Victims were significantly worse off on all the measures in all the samples where a difference was found, while bullies and neutrals did not differ consistently. However, the sex and school type differences were very small and there were several exceptions to the general pattern.

We also hoped that consistent interaction effects would be found, and in this we were less successful. There is little consistent evidence that the relationship between bully/victim status and its social risk factors becomes clearer with age, or is clearer for girls, or that age and sex interact significantly in this respect. So what conclusions can be drawn?

It is encouraging that bully/victim status differences were found so consistently. Large and broadly similar main effects of bully/victim status were found in almost every comparison in the study, suggesting that the four categories (bully, victim, bully-victim, neutral) are reliable and genuine reflections of children's behaviour, regardless of the existence of actual words for "bullying" in the various languages or of other cultural differences between the participating countries. In other words, bullying is a universal phenomenon with serious negative social and emotional correlates for the victims. Differences are large and robust enough to emerge despite methodological weaknesses and statistical noise from a variety of sources, which we consider in more detail below.

The sex effects identified here, though smaller, are also broadly consistent with previous literature, in which many sex differences in the nature of boys' and girls' social networks have been identified. Boys tend to have larger numbers of friends [Bukowski et al., 1993) and that finding was replicated in most of the samples reported here. However, Bukowski et al. also found that, despite this overall difference, there were no differences in the number of reciprocated friends reported by boys and girls. This suggests that simply asking about the number of friends, as in this study, is a rather crude way to assess levels of social support. Similarly, there are sex differences in the nature and quality of friendships, girls typically being more intimate and intense than boys, for whom friendship is more concerned with shared activity [Maccoby, 1999]. This may explain why boys in this study were more frequently alone at breaktimes, despite their higher numbers of friends. Once again, however, our numerical friendship measure does not allow deeper consideration of this issue. Another problem is that we cannot distinguish between same-sex and other-sex friendships: most previous research has tended to focus on same-sex interactions, and there are many differences between children who maintain gender segregation to a greater or lesser extent [Maccoby, 1999]. Finally, we also found that boys enjoyed their breaktimes more than girls did. This may be related to boys' preference for rough-and-tumble play [Pellegrini and Smith, 1998] and for team games that dominate the playground and leave little space for the girls. 
This is why anti-bullying interventions frequently include environmental improvements such as marking out sports areas, to contain these games, and providing seating, gardens, and areas for less active play [Smith and Sharp, 1994].

The pattern of differences identified in our comparisons between primary and secondary schools followed a pattern very similar to the sex differences, primary pupils in most of our samples (like boys) having more friends, enjoying playtimes more but being alone at break more often than their secondary counterparts. We have represented this difference as being primarily one of age, but there are of course many other differences between primary and secondary schools that may help to explain these findings. For example, in many countries, secondary pupils are likely to have less break time, less supervision, and greater freedom to roam the school grounds (or even to leave the school grounds), rather than being restricted to a particular playground. They are also more likely to have different classmates for different lessons, rather than remaining in the same groups throughout the day.

Given the general consistency of these main effects of sex, school type, and bully/victim status, it is perhaps surprising that so few interaction effects were found, and certainly surprising that those which were found did not follow any discernible pattern. In part, this is probably due to the small subgroup sample sizes mentioned earlier, as well as the problem that using single-item measures inevitably produces, rather crude assessments of the various dependent variables. A fair amount of statistical noise is also likely to have been generated by subtle variations in the definitions of bullying or the questionnaire items arising from the translation process. The most interesting variations, however, are those related to cultural differences between the different countries in the study. Although we conclude that bullying is a universal phenomenon, it also seems clear that there are cultural variations in the way that bullying is related to age, sex, and social support. For example, children in collectivist cultures such as China tend to show much more co-operative behaviour and less conflict than those in individualistic cultures such as Britain, Canada, or the USA [see Schneider, 2000, for a review]. Accordingly, shyness is associated with peer rejection in Canada but with popularity in China. Other cultural variables identified by Schneider as being important predictors of social behaviour include tolerance of diversity, "power distance" (the willingness to accept an unequal distribution of power), and the degree to which behaviour is governed by "rules." Cultures also have different attitudes towards sex and age, so that behaviours may be considered acceptable for one sex but not the other, or at one age but not another. There may also be differences in the role of the family and, therefore, in the willingness of children to go outside the family, to teachers for example, for help and support.

In addition to differences in the behaviours under investigation, researchers are also faced with differences in the way people react to research. Participants may value their personal privacy differently, or may feel different pressure to respond in socially acceptable ways. A considerable degree of variation in these factors may be expected both within and between cultures. For example, it may be that it is generally considered less acceptable for girls to be bullies than it is for boys, and so a smaller proportion of female bullies admit to this on completing the questionnaires. Different cultures experience this pressure to a greater or lesser extent, and so we find major differences that may or may not be related to the actual behaviour of the people studied. In the case of sex we can be fairly sure that the girls are under-reporting their bullying behaviour, since the female victims often say that other girls bully them. For other such differences, however, we are in the dark. For this reason, future research should try to utilise multiple methods and pay closer attention to cultural variables, in order to provide a validity check. Similarly, a qualitative approach, such as has been taken 
by Owens et al. [2000], may prove useful, although such research is still likely to be heavily influenced by social expectations: the girls in Owens et al.'s study talked about bullying they had suffered or witnessed, but NOT about behaviours they had performed themselves.

In conclusion, we feel justified in arguing that bullying is a universal phenomenon with many negative correlates for victims but few social consequences for bullies. Secondly, it seems that there are cultural variations in the way that bullying is related to age, sex, and social support that merit further research.

\section{ACKNOWLEDGEMENTS}

We would like to thank Shu Shu, of Goldsmiths College, University of London, for her work on the English national sample.

\section{REFERENCES}

Ahmad Y, Smith PK. 1990. Bullying in school. Newsletter of the Association for Child Psychology and Psychiatry, 12:26-27.

Boulton MJ, Smith PK. 1994. Bully/victim problems in middle-school children: Stability, self-perceived competence, peer perceptions and peer acceptance. Br J Dev Psychol 12:315-329.

Boulton MJ, Underwood K. 1992. Bully victim problems among middle school children. Br J Educ Psychol 62:73-87.

Boulton MJ, Trueman M, Chau C, Whitehand C, Amatya K. 1999. Concurrent and longitudinal links between friendship and peer victimization: implications for befriending interventions. J Adolesc 22:461-466.

Bowers L, Smith PK, Binney V. 1994. Perceived family relationships of bullies, victims and bully/victims in middle childhood. J Soc Pers Relat 11:215-232.

Bukowski WM, Hoza B. 1989. Popularity and friendship: issues in theory, measurement and outcome. In: Berndt TJ, Ladd GW, editors. Peer Relationships In Child Development. New York: Wiley.

Bukowski WM, Gauze C, Hoza B, Newcomb AF. 1993. Differences and consistency between same-sex and other-sex peer relationships during early adolescence. Dev Psychol 29:255-263.

Cicchetti D, Bukowski WM. 1995. Developmental processes in peer relations and psychopathology. Dev Psychopathol 7:587-589.

Genta ML, Menesini E, Fonzi A, Costabile A, Smith PK. 1996. Bullies and victims in schools in central and southern Italy. European Journal of Psychology of Education 11:97-110.

Hodges EVE, Perry DG. 1996. Victims of peer abuse: An overview. Journal of Emotional and Behavioural Problems 5:23-28.
Kochenderfer BJ, Ladd GW. 1996. Peer victimization: Manifestations and relations to school adjustment in kindergarten. J School Psychol 34: 267-283.

Kochenderfer BJ, Ladd GW. 1997. Victimized children's responses to peers' aggression: Behaviors associated with reduced versus continued victimization. Dev Psychopathol 9:59-73.

Maccoby EE. 1999. The Two Sexes: Growing Up Apart, Coming Together. Cambridge, MA: Harvard University Press.

Menesini E, Giannetti E. 1997. Il questionario sulle prepotenze per la popolazione Italiana: problemi teorici e metodologici. In:Fonzi A, editor. Il Bullismo In Italia. Florence: Giunti.

Morita Y, Soeda H, Soeda K, Taki M. 1999. Japan. In: Smith PK, Morita Y, Junger-Tas J, Olweus D, Catalano R, Slee P, editors. The Nature of School Bullying: A Cross-National Perspective. London: Routledge.

Nabuzoka D, Smith PK. 1993. Sociometric status and social behaviour of children with and without learning difficulties. J Child Psychol Psychiatr 34:1435-1448.

Olweus D. 1978. Aggression in the schools: bullies and whipping boys. Washington DC: Hemisphere.

Olweus D. 1991. Bully/victim problems among schoolchildren: basic facts and effects of a school-based intervention program. In: Pepler D, Rubin K, editors. The Development and Treatment of Childhood Aggression, Hillsdale, NJ: Erlbaum.

Olweus D. 1996. The Revised Olweus Bully/Victim Questionnaire. Mimeo. HEMIL, University of Bergen, N-5015 Bergen, Norway.

O'Moore M, Kirkham C. 2001. Self-esteem and its relationship to bullying behaviour. Aggress Behav 27:269-283. 
O'Moore M, Kirkham C, Smith M. 1997. Bullying behaviour in Irish schools: a nationwide study. Irish Journal of Psychology 10:426-441.

Ortega R, Mora-Merchan J. 1999. Spain. In: Smith PK, Morita Y, Junger-Tas J, Olweus D, Catalano R, Slee P, editors, The Nature of School Bullying: A Cross-National Perspective. London: Routledge.

Owens L, Shute R, Slee P. 2000. Guess what I just heard! Indirect aggression among teenage girls in Australia. Aggress Behav 26:67-83.

Pellegrini AD, Smith PK. 1998. Physical activity play: The nature and function of a neglected aspect of play. Child Dev 69:577-598.

Pellegrini AD, Bartini M, Brooks F. 1999. School bullies, victims, and aggressive victims: Factors relating to group affiliation and victimization in early adolescence. J Educ Psychol 91:216-227.

Pellegrini AD, Long JD. 2002. A longitudinal study of bullying, dominance and victimisation during the transition from primary to secondary school. $\mathrm{Br} \mathrm{J}$ Dev Psychol 20:259-280.

Pepler DJ, Craig WM. 1994. Peek Behind The Fence: Naturalistic Observations Of Children Using Video Cameras And Remote Microphones. Poster presented to the $13^{\text {th }}$ Biennial Meetings of the International Society for the Study of Behavioural Development, Amsterdam, The Netherlands.

Pereira B, Almeida A, Valente L, Mendonça D. 1996. O Bullying nas Escolas Portugesas: Análise da variáveis fundamentais para a identificaçãdo problema. In L. Almeida, J. Silvério, \& S. Araújo editors Actas do $2^{\circ}$ Congresso Galacio-Português de Psicopedagogia. Braga: Universidade do Minho. p 71-81.

Perry DG, Kusel SJ, Perry LC. 1988. Victims of peer aggression. Dev Psychol 24:807-814.

Salmivalli C, Lagerspetz KMJ, Björkqvist K, Österman K, Kaukianen A. 1996. Bullying as a group process: participant roles and their relations to social status within the group. Aggress Behav 22:1-15.
Schneider BH. 2000. Friends and Enemies: Peer relations in Childhood. London: Arnold.

Smith PK, Sharp S. 1994. School Bullying: Insights and Perspectives. London: Routledge.

Smith PK, Shu S. 2000. What good schools can do about bullying: findings from a survey of English schools after a decade of research. Childhood 7:193-212.

Smith PK, Madsen KC, Moody JC. 1999a. What causes the age decline in reports of being bullied at school? Educational Research 41:267-285.

Smith PK, Morita Y, Junger-Tas J, Olweus D, Catalano R, Slee P, editors. 1999b. The Nature of School Bullying: A Cross-National Perspective. London: Routledge.

Smith PK, Shu S, Madsen K. 2001. Characteristics of victims of school bullying: developmental changes in coping strategies and skills. In: Juvonen J, Graham S, editors, Peer Harassment in School: The Plight of the Vulnerable and Victimized. New York, NY: Guilford Press.

Smith PK, Cowie H, Olafsson RF, Liefooghe APD. 2002. Definitions of bullying: a comparison of terms used, and age and sex differences, in a 14 country international comparison. Child Development 73:1119-1133.

Wakefield P, Smith N, Wenxin Z, Jones K. 2000. Bullying in China and UK. Paper presented to the International Special Education Conference, University of Manchester. http://www.isec2000.org.uk/ abstracts/papers_w/wakefield.htm

Whitney I, Smith PK. 1993. A survey of the nature and extent of bullying in junior/middle and secondary schools. Educational Research, 35:3-25.

Zhang W, Gu C, Wang M, Wang Y. 2000. Gender differences in bullying \& victimization among primary and junior middle school pupils. Chinese Journal of Psychological Science 23:435-439. 